\title{
Sleep patterns of young children with newly diagnosed atopic dermatitis
}

\author{
Derya Gumus Dogan¹, Sinem Kortay Canaloglu¹, Meltem Kivilcim¹, Yunus Emre Kum², Erdem Topal ${ }^{3}$, Ferhat Catal ${ }^{3}$
}

${ }^{1}$ Department of Developmental Behavioral Pediatrics, School of Medicine, Inonu University, Malatya, Turkey

${ }^{2}$ Department of Pediatrics, Malatya State Hospital, Malatya, Turkey

${ }^{3}$ Department of Allergy, School of Medicine, Inonu University, Malatya, Turkey

Adv Dermatol Allergol 2017; XXXIV (2): 143-147

DOI: https://doi.org/10.5114/ada.2017.67080

\begin{abstract}
Introduction: Even though atopic dermatitis (AD) most often begins in the first year of life, it is not well known whether sleep disturbances occur following the onset of the disease or whether they develop later.

Aim: To determine the sleep patterns of young children already diagnosed with $A D$ in comparison to a control group by using a validated questionnaire, the Brief Infant Sleep Questionnaire (BISQ).

Material and methods: Forty-six children with a new diagnosis of AD and 60 healthy children, aged 3-36 months, participated in the study. Their sleep behaviors were assessed using the BISQ along with a structured sociodemographic data form.

Results: It was found that when compared with healthy children, children with AD did not have decreased daily total sleep duration $(p=0.1)$; however, it was found that they woke up more frequently at night $(52.2 \%$ vs. $40 \%, p=0.4)$ and they stayed awake significantly longer than 60 min when they woke up (41.3\% vs. $11.7 \%, p<0.05)$. In addition, mothers of children with $A D$ reported that their children had three times as many sleep problems compared to the reports of mothers of healthy children.

Conclusions: The findings of this study showed that sleep disturbance was more common in young children with already diagnosed $A D$, and the BISQ provided a practical way to assess the sleep patterns. The use of a screening tool to enable early identification and treatment of childhood sleep problems among patients with AD should be encouraged.
\end{abstract}

Key words: atopic dermatitis, sleep, infancy.

\section{Introduction}

Atopic dermatitis (AD) is a chronic and recurrent inflammatory skin condition that is common in children [1]. The families of children with AD frequently report disturbed sleep [2]. Sleep disturbances have been found to affect $47 \%$ to $60 \%[3,4]$ of school-age patients with AD, due to pruritus and scratching [5].

Delay in sleep onset [6], waking up frequently at night $[6,7]$, and a decrease in sleep duration [6-8] are the most commonly reported sleep problems in these children. Since AD most often begins in the first year of life, a great number of children experience sleep disturbances in the early phases of their development $[9,10]$. Sleep is necessary for a child's cognitive and behavioral development [11]. Infants need to sleep more in the first years of their lives compared to older children, and vari- ous studies have shown that sleep losses in this period of life influence future development and have obvious effects on neurobehavioral and emotional functioning [12-14]. In addition, it has been shown that sleep problems constitute a risk in terms of obesity [15]. In a recent study, concurrent sleeping problems among infants with $A D$ have been found to be a risk factor for the development of mental health problems, such as emotional and behavioral problems, at 10 years of age [16]. Sleep problems affect not only the child with $A D$, but also the quality of life of the family $[17,18]$. Frequent wakings of the child during the night may cause anxiety and depression in the family [19]. In infants with AD, the high prevalence of sleep problems and their negative implications for the whole family emphasize the need for early screening tools that could be used by parents and/or professionals to assess sleep problems.

Address for correspondence: Prof. Derya Gumus Dogan, Department of Developmental Behavioral Pediatrics, School of Medicine, Inonu University, 44280 Malatya, Turkey, phone: +90 050525508 04, fax: +90 422 3410036, e-mail: deryagumus@yahoo.com Received: 21.01.2016, accepted: 14.03.2016. 
The effectiveness of drug treatments for AD can be evaluated by improvement of sleep in patients with this condition. Evaluating infants diagnosed with AD for the first time with a validated instrument for sleep problems will help clinicians observe the effects of AD on sleep problems, their treatment, and the improvement of sleep quality. A great number of studies on the association between $A D$ and sleep have been conducted on preschoolage or older children who have been diagnosed with $A D$ for a long time, and the age ranges of some research groups have been very wide [20, 21].

\section{Aim}

The purpose of this study is to compare sleep problems in infants who are newly diagnosed with AD to those of healthy children, using a validated questionnaire, the Brief Infant Sleep Questionnaire (BISQ) [22]. The BISQ, which was developed for screening sleep disorders in children younger than 3 years of age, met "well-established" assessment criteria according to an evidence-based psychometric review of 21 parent- and child-reported pediatric sleep measures by using the criteria developed by the American Psychological Association Division Evidence-Based Assessment Task Force [23].

\section{Material and methods}

\section{Study design}

This study was a controlled case study of children with a new diagnosis of AD and healthy children. Mothers of children aged 3-36 months who presented to the outpatient clinics of the pediatric allergy division and general pediatrics at Inonu University Turgut Ozal Medical Centre and Malatya State Hospital participated in the study. Patients who were already diagnosed with $A D$ and who had not yet started drug therapy for AD were included in the study. Children with a previous diagnosis of allergy such as allergic rhinitis, and bronchial asthma were not included.

\section{Definitions}

\section{Asthma}

Diagnosis of asthma is based upon a history of at least three wheezing attacks that necessitated treatment with short-acting $\beta 2$ agonists or the patients who were diagnosed previously with asthma by a physician.

\section{Allergic rhinitis}

Diagnosis of allergic rhinitis is based upon the concordance between a typical history of allergic symptoms and skin prick test positivity or the patients who were diagnosed previously with allergic rhinitis by a physician.

\section{Atopic dermatitis}

The AD diagnosis was conducted according to the Hanifin and Rajka criteria based on patient history and clinical characteristics [24]. The diagnosis and severity of $A D$ were documented by a pediatric allergist using the Scoring Atopic Dermatitis (SCORAD) index. Patients were classified according to SCORAD (scoring index of AD) scores. Scores below 25 were classified as mild, those of 25-50 were classified as moderate, and those over 50 were classified as severe atopic dermatitis [25].

The control group included children with no history of allergies, who had come to the hospital for well-child care. Patients who were preterm, who had chronic disease, or who were at risk for developmental delays were excluded from the study since these children can have sleep problems unique to their illnesses. During their clinical visits, the mothers were asked to complete the BISQ and a semi-structured questionnaire designed for this study. The BISQ was verbally administered to the mothers to evaluate sleep patterns, and their answers were recorded directly. The recorded sociodemographic variables included the child's gender, age, and birth order, and the mother's level of education. The Parents' Evaluation of Developmental Status (PEDS) tool was used to detect children at risk for developmental delays [26].

\section{Brief Infant Sleep Questionnaire}

The BISQ is a sleep questionnaire aimed to assess the infant's average sleep patterns; it is a highly validated measure for use with infants and toddlers up to 3 years. The parents are instructed to refer to their infants' regular sleep patterns, and questions are related to the last week's sleep periods. It is easy to administer and can be completed within 5-10 min. The derived measures are: (a) sleep onset time, (b) nocturnal sleep duration, (c) daytime sleep duration, (d) number of night wakings, and (e) sleep latency - the reported length of time it takes the child to fall asleep. The BISQ defines poor sleepers according to one or more of 3 measures; 1 ) child wakes $>3$ times per night, 2) nocturnal wakefulness is $>1 \mathrm{~h}$, or 3) the total sleep time is $<9 \mathrm{~h} \mathrm{[22].}$

The permission for translation of the original English version of the BISQ to Turkish and the use of this questionnaire for clinical purposes was obtained from the original author. The BISQ was translated by two people who knew English and then translated back by another person who did not know about the instrument.

The PEDS is a brief, validated, developmental screening tool to evaluate children ranging in age from birth to 8 years. The tool elicits parental concerns on 10 items across 9 domains of development and behavior. The PEDS has a reported moderate sensitivity (74-79\%) and specificity (70-80\%) [26]. The study was approved by the Ethics Committee of Inonu University, Medical Faculty. 
Written informed consent was obtained from the parents of all of the participants.

\section{Statistical analysis}

All analyses were conducted using SPSS version 16. Descriptive statistical methods were used for demographic information. All data were reported as mean \pm SD. Normality for continued variables in groups was determined by the Shapiro-Wilk test. The Mann-Whitney $U$ test was used for comparison of variables between the studied groups. A value of $p<0.05$ was considered significant.

\section{Results}

Forty-six children currently diagnosed with $A D$ and 60 healthy children aged 3-36 months participated in the study. The participants' average ages were $10.9 \pm 7.7$ and $12.3 \pm 7.7$ for the AD and control groups, respectively. There was no significant difference between age, gender, maternal age, or education variables of the two groups. According to PEDS, none of the children had a developmental problem that made their family anxious. According to SCORAD, the AD severity of children with AD was mild in $58.7 \%$, moderate in $34.8 \%$, and severe in $6.5 \%$. Demographic information is presented in Table 1 . The concerns of the mothers regarding sleep problems in
Table 1. Demographic data of the study subjects

\begin{tabular}{lccc}
\hline Parameter & AD & Healthy & $P$-value \\
\hline Age [months] & $10.9 \pm 7.7$ & $12.3 \pm 7.02$ & $>0.05$ \\
\hline Gender & M: $26(56.5 \%)$ & M: $33(55 \%)$ & $>0.05$ \\
& F: $20(43.5 \%)$ & F: $27(45 \%)$ & \\
\hline Birth weight [g] & $3277.8 \pm 515.1$ & $3218 \pm 396.7$ & $>0.05$ \\
\hline Maternal age [years] & $29.4 \pm 4.5$ & $28.2 \pm 5.1$ & $>0.05$ \\
\hline $\begin{array}{l}\text { Maternal education } \\
\text { lyears] }\end{array}$ & $11.0 \pm 4.0$ & $10.2 \pm 4.5$ & $>0.05$ \\
\hline
\end{tabular}

their children were higher in the AD group than in the control group; $80 \%$ of the mothers of healthy children thought that their children did not have any problems with sleep, 18.3\% thought that their children had some problems with sleep, and $1.7 \%$ thought that their children had serious problems with sleep. Meanwhile, $15.2 \%$ of the mothers of children with AD thought that their children had severe problems with sleep, $41.3 \%$ thought that their children had a small problem with sleep, and $43.5 \%$ thought that their children did not have any problems with sleep $(p<0.001)$.

The average nighttime and daytime sleep durations were longer in the AD infants than in healthy children $(p=0.1)$. Infants with AD had more wakings more often during the night than the control group did $(3.54 \pm 1.8$

Table 2. Sleep characteristics of children with atopic dermatitis and healthy controls

\begin{tabular}{|c|c|c|c|c|}
\hline \multicolumn{2}{|c|}{ BISQ Sleep Measures } & $\mathrm{AD}(n=46)$ & Healthy $(n=60)$ & $P$-value \\
\hline $\begin{array}{l}\text { Location of sleep } \\
n(\%)\end{array}$ & $\begin{array}{l}\text { Infant crib in a separate room } \\
\text { Infant crib in parents' room } \\
\text { In parents' bed } \\
\text { Infant crib in the room with siblings }\end{array}$ & $\begin{array}{c}6(13) \\
30(65.2) \\
5(10.9) \\
5(10.9)\end{array}$ & $\begin{array}{c}2(3.3) \\
42(70) \\
14(23.3) \\
2(3.3)\end{array}$ & 0.05 \\
\hline $\begin{array}{l}\text { Preferred body position } \\
n(\%)\end{array}$ & $\begin{array}{l}\text { On his/her belly } \\
\text { On his/her side } \\
\text { On his/her back }\end{array}$ & $\begin{array}{c}6(13) \\
15(32.6) \\
25(54.3)\end{array}$ & $\begin{array}{l}11(18.3) \\
29(48.3) \\
20(33.3)\end{array}$ & 0.09 \\
\hline $\begin{array}{l}\text { Method of falling asleep } \\
n(\%)\end{array}$ & $\begin{array}{l}\text { While feeding } \\
\text { In bed alone } \\
\text { Being rocked } \\
\text { In bed near parent } \\
\text { Being held }\end{array}$ & $\begin{array}{l}15(32.6) \\
23(50) \\
3(6.5) \\
3(6.5) \\
2(4.3)\end{array}$ & $\begin{array}{l}23(38.3) \\
18(30) \\
11(28.3) \\
7(11.7) \\
1(1.7)\end{array}$ & 0.1 \\
\hline Bedtime, mean \pm SD & & $21.5 \pm 3.3$ & $20.3 \pm 6.1$ & 0.1 \\
\hline Nocturnal sleep duration [min], mean \pm SD & & $556.09 \pm 87.8$ & $516.6 \pm 112.8$ & 0.1 \\
\hline Daytime sleep duration [min], mean \pm SD & & $223.7 \pm 130.7$ & $170.0 \pm 121.4$ & 0.1 \\
\hline Number of night-wakings, mean \pm SD & $>3$ times & $\begin{array}{c}3.54 \pm 1.8 \\
24(52.2 \%)\end{array}$ & $\begin{array}{l}3.02 \pm 1.7 \\
24(40 \%)\end{array}$ & 0.4 \\
\hline Wakefulness time after sleep onset [min] & $\geq 61 \mathrm{~min}$ & $\begin{array}{l}88.3 \pm 76.4 \\
19(41.3 \%)\end{array}$ & $\begin{array}{l}31.9 \pm 47.6 \\
7(11.7 \%)\end{array}$ & 0.005 \\
\hline $\begin{array}{l}\text { Sleep latency/difficulty falling asleep [min], } \\
\text { mean } \pm \text { SD }\end{array}$ & & $28.7 \pm 25.7$ & $25.2 \pm 23.1$ & 0.2 \\
\hline $\begin{array}{l}\text { Do you consider your child's sleep to be } \\
\text { a problem? } \\
n(\%)\end{array}$ & $\begin{array}{l}\text { Serious (major) problem } \\
\text { Small (minor) problem } \\
\text { Not a problem }\end{array}$ & $\begin{array}{c}7(15.2) \\
19(41.3) \\
20(43.5)\end{array}$ & $\begin{array}{c}1(1.7) \\
11(18.3) \\
48(80)\end{array}$ & 0.001 \\
\hline
\end{tabular}


vs. $3.02 \pm 1.7$ wakings, respectively), and the time to fall asleep in infants with AD was longer (28.7 \pm 25.7 vs. 25.2 $\pm 23.1 \mathrm{~min}$, respectively), but these were not statistically different ( $p=0.4$ and $p=0.2$, respectively). In addition, $46.7 \%$ of the infants with AD spent more time in wakefulness during the night in comparison with the control group $(13.7 \%, p=0.005)$. The results are shown in Table 2 .

Most of the healthy children (70.0\%) and infants (65.2\%) with AD preferred sleeping in an infant crib in the parents' room. The belly was the least-preferred body position for both groups. One third of both groups (AD $=32.6 \%$ and control $=38.3 \%$ ) preferred bottle-feeding while falling asleep. There were no differences between the two groups in terms of location of sleep, preferred body position, method of falling asleep, and bedtime. Infants with $A D$ slept longer compared with the control group ( $21.5 \pm 3.3$ vs. $20.3 \pm 6.1 \mathrm{~min}$, respectively); however, this was not statistically significant $(p=0.1)$.

\section{Discussion}

In this study, which assesses the sleep patterns of infants newly diagnosed with AD through a validated sleep tool, it was found that when compared with healthy children, children with AD did not have decreased daily total sleep duration; however, they woke up more frequently at night and stayed awake significantly longer than 60 min when they woke up. In addition, the mothers of children with $A D$ reported that their children had three times as many sleep problems when compared with the reports of mothers of healthy children.

In studies on the sleep patterns of patients with $A D$ from all age groups, the most-reported problems were delays in sleep onset, frequent night wakings, and shorter sleep durations [6-8]. In our study, the long delay in sleep onset, the higher number of night wakings, and the longer periods of falling asleep after wakings in children with $A D$ showed that the sleeping duration of these children will continue to decrease in the future; however, the study also shows that the sleeping duration of these children is not affected at the onset of the disease. A community-based study conducted with 4,085 1-year-old children in Taiwan showed that sleep duration decreased and the frequency of wakings at night increased in children with $A D$ when compared with the control group. In this study, which showed that sleep disturbances occur at the onset of the disease, AD was diagnosed by showing 3 pictures of typical AD to families, and sleep behavior was evaluated with an unstructured questionnaire [27]. In another study conducted in England, which compared 44 children with AD to a control group, whose ages ranged between 5 months to 3 years, it was found that children with AD were more likely to have night-waking problems and it took them longer to resettle during the night [28].
In infants with $A D$, the frequency of waking up more than 3 times a night and the period of resettlement being longer than $1 \mathrm{~h}$ may cause the mothers to think that their children have sleep problems. In another study, it was found that mothers thought that the factor most associated with poor sleep was night-wakings [29].

The strongest point of our study is the assessment of sleep patterns with a tool that is used for infants in many countries. Another strength of our study is comparing the sleep behaviors of similar age groups, since a great number of the existing studies have been conducted using a wide age range although sleep physiology changes with age. The major limitation of the study is a small number of participants who attended the current study. Therefore, our findings need to be supported with studies which have a large number of participants. However, the fact that it is the first study that assessed sleep patterns of young children with newly diagnosed atopic dermatitis. Sleep disturbance is strongly associated with disease severity. In a study conducted by Chang on allergic preschoolers, it was found that patients with moderate to severe AD had more sleep problems [30]. Because of the small numbers of patients, we were not able to compare the AD patients' sleep status with each other. Another limitation of the study is that only the data on patients admitted to the hospital are presented; therefore, this cannot be generalized to apply to all patients with AD.

The number of severe, moderate, or mild AD cases in our study was not enough to compare or to detect a difference if one existed.

\section{Conclusions}

The absence of an immediate decrease in sleep duration during the diagnosis of AD can make interventions to fix sleep problems more effective. Interventions to improve children's sleep habits, especially in early childhood, are likely to improve the quality of life of the whole family [31]. For this reason, it is important for clinicians who work with children with AD to study the influence of this condition's treatment on sleep and to try to obtain sleep improvement as well as improvement of skin issues. We recommend that clinicians advise parents about behavioral sleep problems that may be due to the stressful effects of the skin condition.

\section{Conflict of interest}

The authors declare no conflict of interest.

\section{References}

1. Boguniewicz M. Atopic dermatitis: beyond the itch that rashes. Immunol Allergy Clin North Am 2005; 25: 333-51.

2. Chamlin SL, Mattson CL, Frieden IJ, et al. The price of pruritus: sleep disturbance and cosleeping in atopic dermatitis. Arch Pediatr Adolesc Med 2005; 159: 745-50. 
3. Hon KL, Leung TF, Wong KY, et al. Does age or gender influence quality of life in children with atopic dermatitis? Clin Exp Dermatol 2008; 33: 705-9.

4. Lewis-Jones S. Quality of life and childhood atopic dermatitis: the misery of living with childhood eczema. Int J Clin Pract 2006; 60: 984-92.

5. Gupta MA, Gupta AK. Sleep-wake disorders and dermatology. Clin Dermatol 2013; 31: 118-26.

6. Dahl RE, Bernhisel-Broadbent J, Scanlon-Holdford S, et al. Sleep disturbances in children with atopic dermatitis. Arch Pediatr Adolesc Med 1995; 149: 856-60.

7. Stores G, Burrows A, Crawford C. Physiological sleep disturbance in children with atopic dermatitis: a case control study. Pediatr Dermatol 1998; 15: 264-8.

8. Shani-Adir A, Rozenman D, Kessel A, et al. The relationship between sensory hypersensitivity and sleep quality of children with atopic dermatitis. Pediatr Dermatol 2009; 26: 143-9.

9. Bonifazi E, Meneghini CL. Atopic dermatitis in the first six months of life. Acta Derm Venereol Suppl (Stockh) 1989; 144: 20-2.

10. Küster W, Petersen M, Christophers E, et al. A family study of atopic dermatitis. Clinical and genetic characteristics of 188 patients and 2,151 family members. Arch Dermatol Res 1990; 282: 98-102.

11. Chng SY. Sleep disorders in children: the Singapore perspective. Ann Acad Med Singapore 2008; 37: 706-9.

12. Ednick M, Cohen AP, McPhail GL, et al. A review of the effects of sleep during the first year of life on cognitive, psychomotor, and temperament development. Sleep 2009; 32: 1449-58.

13. Bernier A, Carlson SM, Bordeleau S, et al. Relations between physiological and cognitive regulatory systems: infant sleep regulation and subsequent executive functioning. Child Dev 2010; 81: 1739-52.

14. Scher A. Infant sleep at 10 months of age as a window to cognitive development. Early Hum Dev 2005; 81: 289-92.

15. Taveras EM, Rifas-Shiman SL, Oken E, et al. Short sleep duration in infancy and risk of childhood overweight. Arch Pediatr Adolesc Med 2008; 162: 305-11.

16. Schmitt J, Chen CM, Apfelbacher C, et al. Infant eczema, infant sleeping problems, and mental health at 10 years of age: the prospective birth cohort study LISAplus. Allergy 2011; 66: 404-11.

17. Lewis-Jones MS, Finlay AY, Dykes PJ. The infants' dermatitis quality of life index. Br J Dermatol 2001; 144: 104-10.

18. Kiebert G, Sorensen SV, Revicki D, et al. Atopic dermatitis is associated with a decrement in health-related quality of life. Int J Dermatol 2002; 41: 151-8.

19. Lawson V, Lewis-Jones MS, Finlay AS, et al. The family impact of childhood atopic dermatitis: the Dermatitis Family Impact Questionnaire. Br J Dermatol 1998; 138: 107-13.

20. Dahl RE, Bernhisel-Broadbent J, Scanlon-Holdford S, et al. Sleep disturbances in children with atopic dermatitis. Arch Pediatr Adolesc Med 1995; 149: 856-60.

21. Chang YS, Chou YT, Lee JH, et al. Atopic dermatitis, melatonin, and sleep disturbance. Pediatrics 2014; 134: e397-405.

22. Sadeh A. A brief screening questionnaire for infant sleep problems: validation and findings for an Internet sample. Pediatrics 2004; 113: e570-7.

23. Lewandowski AS, Toliver-Sokol M, Palermo TM. Evidencebased review of subjective pediatric sleep measures. J Pediatr Psychol 2011; 36: 780-93.

24. Hanifin JM, Rajka G. Diagnostic features of atopic dermatitis. Acta Derm Venereol 1980; 92: 44-7.
25. Oranje AP, Glazenburg EJ, Wolkerstorfer A, et al. Practical issues on interpretation of scoring atopic dermatitis: the SCORAD index, objective SCORAD and the three-item severity score. Br J Dermatol 2007; 157: 645-8.

26. Glascoe FP, MacLean WE, Stone WL. The importance of parents' concerns about their child's behavior. Clin Pediatr (Phila) 1991; 30: 8-11.

27. Anuntaseree W, Sangsupawanich P, Osmond C, et al. Sleep quality in infants with atopic dermatitis: a communitybased, birth cohort study. Asian Pac J Allergy Immunol 2012; 30: 26-31.

28. Chamlin SL, Mattson CL, Frieden IJ, et al. The price of pruritus: sleep disturbance and co-sleeping in atopic dermatitis. Arch Pediatr Adolesc Med 2005; 159: 745-50.

29. Mindell JA, Du Mond CE, Sadeh A, et al. Efficacy of an internet-based-intervention for infant and toddler sleep disturbances. Sleep 2011; 34: 451-8.

30. Chang HY, Seo JH, Kim HY, et al. Allergic diseases in preschoolers are associated with psychological and behavioural problems. Allergy Asthma Immunol Res 2013; 5: 315-21.

31. Mindell JA, Sadeh A, Wiegand B, et al. Cross-cultural differences in infant and toddler sleep. Sleep Med 2010; 11: 274-80. 